\title{
Use and Acceptability of Birth Spacing Contraceptive Among Multiparae in Bangladesh
}

\author{
Kamrun Nahar, Taqbir Us Samad Talha, Amitun Nessa, I. Gusti Ngurah Edi Putra, \\ Zubair Ahmed Ratan, and Hassan Hosseinzadeh
}

\section{ABSTRACT}

Background: Contraception is one of the critical components of reproductive health, enabling women to control their fertility according to their desires and circumstances. This study aimed to determine the prevalence and acceptability of contraceptives among sexually active multiparous women for birth spacing.

Methods: This is a cross-sectional study among married women aged 1540 years having at least one child from January to June 2013 in the Department of Obstetrics and Gynecology, ICMH (Institute of Child and Mother Health), Matuail, Dhaka.

Findings: A total of $\mathbf{4 3 3}$ women participated in this study. A majority of the respondents were in the mid-thirty $(\mathbf{7 3 . 9 \%})$ and housewives $(94.7 \%)$. Almost half $(49.0 \%)$ of the respondents had primary education. Surprisingly, close to half of the respondents married before 18 years $(42.7 \%)$. Almost two-thirds $(64.4 \%)$ of the respondents received oral contraceptive pills previously, followed by condoms $(17.1 \%)$ and injectable contraception $(14.5 \%)$. More than half $(51.6 \%)$ of the participants were motivated by health workers to use a contraceptive method. In terms of reasons for using the family planning methods, convenience to use $(38.1 \%)$, being safe $(31.9 \%)$, and accessibility $(23.1 \%)$ were the most common reasons. Whereas side effects $(49.9 \%)$, shifting to other forms $(43.9 \%)$, and wanting more children $(6.2 \%)$ were the most common reason for changing family planning methods. The respondents mostly used the oral pill at any education level. However, injectable contraception was higher within higher education levels, and IUD was higher within the illiterate group.

Keywords: Acceptability, Bangladesh, contraception, multiparae.
Published Online: December 7, 2021

ISSN: $2736-5476$

DOI: $10.24018 /$ ejclinicmed.2021.2.6.114

K. Nahar

Department Obstetrics and Gynecology, Institute of Child and Mother Health (ICMH), Matuail, Dhaka, Bangladesh.

T. U. S. Talha

Department of Anthropology, Jahangirnagar University, Savar, Dhaka1342, Bangladesh.

A. Nessa

Department Obstetrics and Gynaecology, Mugda Medical College and Hospital, Mugda, Dhaka, Bangladesh.

I. G. N. E. Putra

School of Health \& Society, University of Wollongong, NSW, Australia.

Z. A. Ratan*

School of Health \& Society, University of Wollongong, NSW, Australia.

Department of Biomedical Engineering,

Khulna University of Engineering and Technology, Bangladesh.

(e-mail: ratandmck62@gmail.com)

H. Hosseinzadeh

School of Health \& Society, University of Wollongong, NSW, Australia.

*Corresponding Author

\section{INTRODUCTION}

Family planning shows excellent promise in Bangladesh; however, lack of knowledge and education, negative myths, and misconceptions about family planning are the potential barriers to contraceptive use [1]. In Bangladesh, the female population is about 81.3 million [2], and the total fertility rate (TFR) declined from 6.3 births per woman in 1971-75 to 3.3 births per woman in 1972-95 [3]. There was a long plateau in fertility between 1994 and 2004 at around 3.3 [3]. Bangladesh has experienced a sharp decline in child mortality and total fertility rate in the past decades. Further reducing child mortality and total fertility remains a significant concern, intending to achieve the United Nations Millennium Development Goals 4 and 5 [4].

Birth rates are vital indicators for economic and social welfare planning, and the effectiveness of birth spacing methods is directly linked to birth rate [5]. Overall, 61 percent of currently married women in Bangladesh are now using a contraceptive method. The majority of women use a modern method (52\%), and $9 \%$ use traditional methods. The pill is by far the most widely used method $(27 \%)$, followed by injectable $(11 \%)$, female sterilization $(5 \%)$, and condoms $(6 \%)$ [3].

However, in Bangladesh, contraception studies mainly focusing on contraceptives' side effects are limited [6]. This study aimed to fill this gap by determining the proportion of contraceptive methods to achieve birth spacing among multipara attending the outpatient department of ICMH. The study also assessed the proportion of contraceptive methods to achieve birth spacing and side effects among multipara according to their parity, occupation, socioeconomic status, and educational status.

\section{MATERIALS AND METHODS}

The research was carried out among 433 married women aged 15-40 years having at least two children, attending in OPD (Outpatient Department treatment) in the Departments of Gynecology \& Obstetrics of ICMH (Institute of Child and 
Mother Health), from January to June 2013, using a selfadministered questionnaire. A non-random and convenient sampling method was used for eligible participants' recruitment.

\section{A. Procedure}

Before data collection, informed written consent was taken from the eligible respondents. Participation was voluntary, and the participant can withdraw at any time without any penalty. Privacy of the participants was maintained during data. The study was approved by the ethical committee.

\section{B. Inclusion/Exclusion Criteria}

Participants were eligible if they were: (i) aged $15-40$ years old, (ii) married, and (iii) having at least two children. The eligible participants were excluded if they were divorced, widows, or separated.

\section{Statistics}

Statistical analysis was carried out using the Statistical Package for Social Sciences version 26.0 for Windows (SPSS Inc., Chicago, Illinois, USA). The mean values were calculated for continuous variables. The quantitative observations were indicated by frequencies and percentages.

\section{RESULTS}

A total of 433 consecutive married people aged 15-40 years, having at least two children, attending OPD in the Departments of Gynecology \& Obstetrics of ICMH from January 2013 to June 2013 enrolled in this study.

According to age, the majority $(73.9 \%)$ of respondents were found in the $3^{\text {rd }}$ decade, and the mean age was $27.0 \pm 4.6$ years.

Regarding the occupational status of the respondents, most $410(94.7 \%)$ respondents were housewives, followed by 14 $(3.2 \%)$ service holders, $5(1.2 \%)$ day labour, and $4(0.9 \%)$ involved with other occupations.

Concerning educational background, the above table shows that almost half $(49.0 \%)$ respondents had primary education followed by 107 (24.6\%) SSC level, 71 (16.4\%) HSC \& above, and 43 (9.9\%) respondents were illiterate.

The Table I also shows that $185(42.7 \%)$ respondents were married before 18 years, and only $1(0.2 \%)$ married after 30 years.

About the number of children, most $315 \quad(72.3 \%)$ respondents mentioned that they had 2 children, $91(21.0 \%)$ had 3 children, $27(6.2 \%)$ had 4 and above children.

Table II shows that almost two-thirds $(64.4 \%)$ of the respondents received oral contraceptive pills previously, $17.1 \%$ used condoms, $14.5 \%$ received Injectable, $0.7 \%$ received nor plant, and $6(1.4 \%)$ IUD and $1.8 \%$ used other methods.

About motivational status for using FP methods, 210 (48.4\%) were self-motivated, and 223 (51.6\%) were motivated by health workers to use contraceptives.

More than a half $(52.7 \%)$ respondents currently received an oral contraceptive pill, (18.9\%) used condom and $74(17.1 \%)$ received injectable, $15(3.5 \%)$ received IUD, $7(1.6 \%)$ used received, nor plant and $27(6.2 \%)$ respondents used others family planning methods. A majority, 349 $(69.8 \%)$, of the respondents using the current family planning method for more than 1 year.

TABLE I: SOCIO-DEMOGRAPHIC CHARACTERISTICS OF PARTICIPANTS $(\mathrm{N}=433)$

\begin{tabular}{|c|c|c|}
\hline Variable & Number & Percentage \\
\hline \multicolumn{3}{|c|}{ Age (years) } \\
\hline$\leq 20$ & 25 & 5.8 \\
\hline $21-30$ & 320 & 73.9 \\
\hline $31-40$ & 83 & 19.2 \\
\hline$>40$ & 5 & 1.2 \\
\hline \multicolumn{3}{|c|}{ Age } \\
\hline Mean $( \pm \mathrm{SD})$ & \multirow{2}{*}{\multicolumn{2}{|c|}{$\begin{array}{c}27.0 \pm 4.6 \\
(18-40)\end{array}$}} \\
\hline Range (min-max) & & \\
\hline \multicolumn{3}{|c|}{ Occupation } \\
\hline Housewife & 410 & 94.7 \\
\hline Service holder & 14 & 3.2 \\
\hline Day labor & 5 & 1.2 \\
\hline Others & 4 & 0.9 \\
\hline \multicolumn{3}{|l|}{ Education } \\
\hline Illiterate & 43 & 9.9 \\
\hline Primary & 212 & 49.0 \\
\hline $\mathrm{SSC}^{\circ}$ & 107 & 24.6 \\
\hline HSC and above & 71 & 16.4 \\
\hline \multicolumn{3}{|c|}{ Age at marriage (years) } \\
\hline$<18$ & 185 & 42.7 \\
\hline $18-20$ & 139 & 32.1 \\
\hline $21-25$ & 105 & 24.2 \\
\hline $26-30$ & 3 & 0.7 \\
\hline$>30$ & 1 & 0.2 \\
\hline \multicolumn{3}{|c|}{ Age } \\
\hline Mean $( \pm \mathrm{SD})$ & \multirow{2}{*}{\multicolumn{2}{|c|}{$\begin{array}{c}17.0 \pm 3.0 \\
(12-38)\end{array}$}} \\
\hline Range (min-max) & & \\
\hline \multicolumn{3}{|c|}{ Number of children } \\
\hline 2 children & 315 & 72.3 \\
\hline 3 children & 91 & 21.0 \\
\hline 4 and above & 27 & 6.2 \\
\hline
\end{tabular}

Regarding the reasons for using the current family planning methods, $38.01 \%$ of respondents mentioned that convenience to use, $31.9 \%$ said safe and $23.1 \%$ mentioned accessibility, $3.9 \%$ health worker advised, and $3.0 \%$ mentioned less cost.

Concerning reasons of changing family planning methods (49.9\%) side effect followed by $43.9 \%$ change of choice to one method, $6.2 \%$ want children.

Respecting the experienced discomfort due to using contraceptive methods, most $(42.1 \%)$ respondents mentioned nausea, 31.0\% headache, $29.6 \%$ about $\mathrm{P} / \mathrm{V}$ bleeding/pain, and $13.0 \%$ about vomiting.

Maximum $87.5 \%$ of the respondents did not face any obstacles to adopting contraceptives, 5.5\% faced husband objection, 3.2\% faced religious objection, and 3.8\% faced others' disapproval. 54 respondents faced an obstacle, out of which $44.4 \%$ overcome obstacles by self-motivation, $25.9 \%$ by husband support, and $29.6 \%$ by family planning worker advice.

More than half (53.1\%) of the respondents collected family planning methods from a pharmacy, followed by $40.9 \%$ from family planning workers, $6.0 \%$ from NGOs. Maximum $98.4 \%$ of the respondents mentioned that their family planning methods were available.

Table III shows that at any educational level, the respondents mostly used the oral pill. Injectable was significantly higher in higher education levels, and IUD was higher in the illiterate class. 
TABLE II: STATUS, BARRIERS AND MOTIVATIONS OF USING FP METHODS $(\mathrm{N}=433)$

\begin{tabular}{|c|c|c|}
\hline Variable & Number & Percentage \\
\hline \multicolumn{3}{|c|}{ Previously used family planning methods } \\
\hline Oral pill & 279 & 64.4 \\
\hline Condom & 74 & 17.1 \\
\hline Injectable & 63 & 14.5 \\
\hline Nor plant & 3 & 0.7 \\
\hline IUD & 6 & 1.4 \\
\hline Others & 8 & 1.8 \\
\hline \multicolumn{3}{|c|}{ Motivational status for using FP methods } \\
\hline Self-motivation & 210 & 48.4 \\
\hline Motivated by health workers & 223 & 51.6 \\
\hline \multicolumn{3}{|l|}{ Currently used FP methods } \\
\hline Oral pill & 228 & 52.7 \\
\hline Condom & 82 & 18.9 \\
\hline Injectable & 74 & 17.1 \\
\hline Nor plant & 7 & 1.6 \\
\hline IUD & 15 & 3.5 \\
\hline Others & 27 & 6.2 \\
\hline \multicolumn{3}{|l|}{ How long using current FP methods } \\
\hline$<1$ year & 349 & 69.8 \\
\hline$>1$ year & 151 & 30.2 \\
\hline \multicolumn{3}{|c|}{ Reasons for using current FP methods } \\
\hline Convenience to use & 165 & 38.1 \\
\hline Safe & 138 & 31.9 \\
\hline Accessible & 100 & 23.1 \\
\hline Health worker advised & 17 & 3.9 \\
\hline Less cost & 13 & 3.0 \\
\hline \multicolumn{3}{|l|}{ Reasons for changing FP methods } \\
\hline Side effect & 216 & 49.9 \\
\hline Change of choice & 190 & 43.9 \\
\hline Want Children & 27 & 6.2 \\
\hline \multicolumn{3}{|c|}{ Side effects of using FP methods $(n=216)$} \\
\hline Nausea & 91 & 42.1 \\
\hline Headache & 67 & 31.0 \\
\hline $\mathrm{P} / \mathrm{V}$ bleeding/pain & 64 & 29.6 \\
\hline Vomiting & 28 & 13.0 \\
\hline \multicolumn{3}{|l|}{ An obstacle to adopting FP methods } \\
\hline No obstacle & 379 & 87.5 \\
\hline Husband objection & 23 & 5.5 \\
\hline Religious objection & 14 & 3.2 \\
\hline Other's objection & 17 & 3.8 \\
\hline \multicolumn{3}{|c|}{ Overcome the obstacle to use FP methods $(n=54)$} \\
\hline Self-motivation & 24 & 44.4 \\
\hline Husband support & 14 & 25.9 \\
\hline Family planning worker's advice & 16 & 29.6 \\
\hline \multicolumn{3}{|l|}{ Source of FP methods } \\
\hline Pharmacy & 230 & 53.1 \\
\hline Family planning worker & 177 & 40.9 \\
\hline NGOs Clinic & 26 & 6.0 \\
\hline \multicolumn{3}{|l|}{ Availability of FP methods } \\
\hline Available & 426 & 98.4 \\
\hline Not available & 7 & 1.6 \\
\hline
\end{tabular}

\section{Discussion}

This cross-sectional study was carried out to determine the common method used among multiparae and women's views regarding birth spacing contraception. Current contraceptive practice depends on people's fertility desires, availability, and quality of family planning services. Social factors also affect the acceptability of contraceptive use. Again, this contraceptive use level also directly affects the total fertility rate (TFR) and population growth rate. Ever use of any method increases with women's age up to 30-34 years, reflecting that, as with age, their fertility goals are fulfilled, and women increasingly adopt contraception [7]. A decline in ever use of contraceptive methods at older generations indicates lower contraceptive prevalence in the past. In this current study, the majority $(73.9 \%)$ of respondents were found in the 3rd decade of life, and the mean age was $27.0 \pm 4.6$ years, with a range from 18 to 40 years.

Regarding the respondents' occupational status of the respondents, it was observed that most $(94.7 \%)$ of the respondents were housewives, followed by a $3.2 \%$ service holder and 1.2\%-day labour. Previously, [8] reported that the majority $92 \%$ were housewives and 5\% service holders and $5 \%$-day labour. The above findings are consistent with the current study. Regarding educational qualification, almost half $(49.0 \%)$ had primary education followed by $24.6 \% \mathrm{SSC}$ level, 16.4\% HSC \& above, and $10.0 \%$ were illiterate. A study done by [8] found $28 \%$ were illiterate in our country, $55 \%$ had a primary level, $9 \%$ had a secondary level, and $8 \%$ had higher secondary. Reference [9] showed $11.21 \%$ were illiterate, $26.45 \%$ were primary level, $42.15 \%$ were secondary level, $13.45 \%$ were higher secondary, and $6.72 \%$ were graduate. Thus, education is one of the significant parameters that influence the attitude and abilities of women. Attitudes towards the acceptability of media messages are highly favorable among women who have completed primary school and above and those below 30 years of age. However, [7] reported that family planning is more acceptable to younger women.

TABLE III: EFFECT OF EDUCATION ON CONTRACEPTIVE CHOICE (N=433)

\begin{tabular}{ccccccc}
\hline \hline $\begin{array}{c}\text { Contraceptive } \\
\text { choice }\end{array}$ & Total N & $\begin{array}{c}\text { Illiterate } \\
\mathrm{n}(\%)\end{array}$ & $\begin{array}{c}\text { Primary } \\
\mathrm{n}(\%)\end{array}$ & $\begin{array}{c}\text { SSC } \\
\mathrm{n}(\%)\end{array}$ & $\begin{array}{c}\text { HSC and above } \\
\mathrm{n}(\%)\end{array}$ & P-value \\
\hline \hline Oral pill & 229 & $18(41.9)$ & $115(54.2)$ & $59(55.1)$ & $36(50.7)$ & $0.457^{\text {ns }}$ \\
Condom & 82 & $10(23.3)$ & $46(21.7)$ & $19(17.8)$ & $7(9.9)$ & $0.139^{\text {ns }}$ \\
Injectable & 74 & $6(14.0)$ & $27(12.7)$ & $18(16.8)$ & $23(32.4)$ & $0.001^{\mathrm{s}}$ \\
Nor plant & 7 & 0 & $4(1.9)$ & $1(0.9)$ & $2(2.8)$ & $0.623^{\text {ns }}$ \\
IUD & 15 & $5(11.6)$ & $9(4.2)$ & $1(0.9)$ & $0(0.0)$ & $0.003^{\mathrm{s}}$ \\
Not used & 27 & $4(9.3)$ & $11(5.2)$ & $9(8.4)$ & $3(4.2)$ & $0.485^{\text {ns }}$ \\
Total & 433 & 43 & 212 & 107 & 71 & \\
\hline \hline
\end{tabular}

This current series observed that $42.7 \%$ of respondents were married before 18 years, and only $0.2 \%$ married after 30 years. Reference [8] conducted a study in Bangladesh and reported that the patients' age during the marriage was between $16-20$ years, $79.6 \%, 18.8 \%$ were $21-25$ years, and only $1.6 \%$ were beyond $25 \%$. Only small proportions of evermarried women begin using contraception when they did not have any living child. Although contraception before the first child's birth is relatively uncommon, most ever-users (threefifth) initiate contraception when they have three or fewer living children documented by [7]. Parity is a significant determinant in the use of contraception. As analyzed from the Princeton fertility survey (USA), birth rates were lower among those who had achieved their desired number of children and now wanted to stop childbearing than those who wanted more children. This study observed that most $(72.3 \%)$ of the respondents mentioned that they had 2 children, $21.0 \%$ had 3 children, and $6.2 \%$ had 4 and above children. It was also observed that almost two-thirds $(64.4 \%)$ of the respondents received oral contraceptive pills previously, 
$17.1 \%$ used condoms, $14.5 \%$ received injectables, $11.40 \%$ use condoms, $0.44 \%$ used sterilization, and $0.82 \%$ use the traditional method. Reference [6] mentioned that about $86.0 \%$ of mothers use any contraceptive method after giving birth. Reference [7] reported that the most commonly everused methods are Intra-Uterine Devices (about one-sixth), condoms (nearly one-eighth), and female sterilization (twothird). No male sterilization is reported in this study.

Countries differ in both the number of methods offered and the extent to which each is made available. Information is needed on how these factors have changed over time and how they have affected contraceptive use overall and individual methods. Studies from developing countries show each method's availability rose substantially, from $25 \%$ to $35 \%$ for female sterilization, from $34 \%$ to $61 \%$ for the pill, from $26 \%$ to $50 \%$ for the IUD, and $34 \%$ to $63 \%$ for the condom [10]. However, five years later, in the 1999 ratings for 88 countries, only $65 \%$ of countries offered the pill to at least half their population, $54 \%$ the IUD, $42 \%$ female sterilization, $26 \%$ male sterilization, and $73 \%$ the condom [11].

In this present study, it was observed that almost half $(48.4 \%)$ of the respondents were self-motivated, and $51.6 \%$ were motivated by health workers to use contraceptives. In our country, [8] found $50.1 \%$ inspired by health workers about contraceptive methods, $42.7 \%$ self-motivated, and $7.2 \%$ by husband, closely resembling the present study. In this current series, it was observed that more than half $(52.7 \%)$ of the respondents currently received an oral contraceptive pill, $18.9 \%$ used condoms, and $17.1 \%$ received injectable, $1.6 \%$ received nor plant, and 3.5\% received IUD. In a study, [7] mentioned that current contraceptive prevalence, like that of ever use, is high among Gujjars. Three out of every five currently married women are using some of the other methods of contraception. Most recently married women $(80.0 \%)$, who have ever used a contraceptive, are presently using a method.

In this current series, it was observed that more than twothirds $(69.8 \%)$ of the respondents using the current family planning method for more than one year. The average birth interval is about $9 \%$ longer if a mother continuously uses a method for more than three years, compared to seven months to three years [6]. Regarding the side effect of using the contraceptive method, it was observed in this current study that $42.1 \%$ reported nausea, $31.0 \%$ headache, $29.6 \% \mathrm{P} / \mathrm{V}$ bleeding/pain, and $13.0 \%$ mentioned vomiting. Reference [12] The most common side effects include nausea, headache, breast tenderness, weight gain, irregular bleeding, and $\mathrm{P} / \mathrm{V}$ bleeding or pain.

Regarding reasons for the non-use of contraceptives, [7] reported health-related problems, worrying about side effects. Less than ten percent believe that it is difficult to get pregnant if one uses contraceptives after the contraceptive is discontinued. About $11.0 \%$ of women are not interested in family planning [7]. In this present study, it was observed that a maximum $(87.5 \%)$ of the respondents mentioned that they face no obstacle to adopt contraceptives, $5.6 \%$ face obstacles by husband, 3.2\% noted religious cause, and 3.7\% faced obstacles by others. Reference [8] reported that $12.6 \%$ face obstacles by husband, $3.0 \%$ face obstacles by a family member, and $7.1 \%$ mentioned religion, which is comparable with the present study.
A total of 54 respondents faced obstacles in this current series, out of which $44.4 \%$ overcome obstacles by selfmotivation, $25.9 \%$ by husband, and $29.6 \%$ by family planning worker. Reference [8] showed that $22.7 \%$ had barriers. $12.6 \%$ were self, $6.1 \%$ doctor family planning workers, and $4.0 \%$ husbands. Family planning methods and services in Bangladesh are provided by the private sector and the public sector. Through a network of private sectors are hospitals/clinics, NGOs, pharmacy, and other private sources. Besides these under the public sector, family planning services are also provided by government hospitals, family welfare centers, Upazila health complexes, satellite clinics, maternal and child welfare centers, government field workers, and other public sources. The public sector is the primary source of pills and IUDs. In this current series, it was observed that more than half $(53.1 \%)$ of the respondents collected family planning methods from the pharmacy, followed by $40.9 \%$ from family planning workers and $6.0 \%$ from the NGO clinic.

Regarding the association between education level with contraceptive choice, it was observed in this current study that the oral pill was used mainly by the respondents having any education level. Injectable was significantly higher in higher education levels (32.4\%), and IUD was higher in the illiterate class $(11.6 \%)$.

\section{CONCLUSION}

This study was undertaken to assess the acceptability of various contraceptive methods to achieve birth spacing among multiparae attending the OPD of ICMH. Most of the respondents were in the $3^{\text {rd }}$ decade, primary level of education, and primarily housewives. The oral contraceptive pill was more common contraceptive and more frequent at any education level; however, injectable was higher at higher education level, and IUD was more common at an illiterate level. A particular contraceptive method was convenient to use, safe and accessible, which were the more common reasons to use a specific contraceptive method.

\section{REFERENCES}

[1] Najafi-Sharjabad F, Yahya SZS, Rahman HA, Hanafiah M, Manaf RA. Barriers of modern contraceptive practices among Asian women: a mini literature review. Global Journal of Health Science. 2013; 5(5): 181.

[2] Bangladesh Bureau of Statistics [BBS]. [Internet]. 2018. Available from:

http://bbs.portal.gov.bd/sites/default/files/files/bbs.portal.gov.bd/page/ a1d32f13_8553_44f1_92e6_8ff80a4ff82e/Bangladesh\%20\%20Statisti cs-2018.pdf

[3] Javanbakht M, Baradaran HR, Mashayekhi A, Haghdoost AA, Khamseh ME, Kharazmi E, et al. Cost-of-illness analysis of type 2 diabetes mellitus in Iran. PloS One. 2011; 6(10): e26864.

[4] Koblinsky M, Anwar I, Mridha MK, Chowdhury ME, Botlero R. Reducing maternal mortality and improving maternal health: Bangladesh and MDG 5. Journal of Health, Population, andNutrition. 2008; 26(3): 280.

[5] Lindo JM, Packham A. How much can expanding access to long-acting reversible contraceptives reduce teen birth rates?. American Economic Journal: Economic Policy. 2017; 9(3): 348-76.

[6] van Soest A, Saha U. Does family planning reduce infant mortality? Evidence from surveillance data in Matlab, Bangladesh, 2012.

[7] Dabral S, Malik SL. Demographic study of Gujjars of Delhi: IV. KAP of family planning. Journal of Human Ecology. 2004; 16(4): 231-237. 
[8] Khan NR, Jerifa S. Prevalence of contraceptive use among married women of reproductive age groups in a rural area of Bangladesh. Journal of Dhaka Medical College. 2014; 23(1): 7-13.

[9] Islam MZ, Shaila H, Farzana Z. Reproductive health profile of married women: experience from a rural community of Bangladesh. Bangladesh Journal of Medical Science. 2011; 10(4): 252-256.

[10] Ellertson C, Koenig J, Trussell J, Bull J. How many US women need emergency contraception. Contemp Ob Gyn. 1997; 42: 102-128.

[11] Winner B, Peipert JF, Zhao Q, Buckel C, Madden T, Allsworth JE, et al. Effectiveness of long-acting reversible contraception. New England Journal of Medicine. 2012; 366(21): 1998-2007.

[12] Ross J, Hardee K, Mumford E, Eid S. Contraceptive method choice in developing countries. International Family Planning Perspectives. 2002: 32-40 